\title{
Long-acting reversible hormonal contraception
}

\author{
NE Dahan-Farkas, ${ }^{\text {a MOE Irhuma*a }}$ \\ aDivision of Clinical and Experimental Pharmacology, Department of Pharmacy and Pharmacology, School of Therapeutic Sciences \\ Faculty of Health Sciences, University of Witwatersrand, Johannesburg \\ *Corresponding author, email: mohamed.irhuma@wits.ac.za
}

\begin{abstract}
Long-acting reversible hormonal contraceptives are effective methods of birth control that provide contraception for an extended period without requiring user action. Long-acting reversible hormonal contraceptives include progesterone only injectables, subdermal implants and the levonorgestrel intrauterine system. These methods have several advantages over other reversible contraceptive methods. More importantly, once in place, they require minimal maintenance and their duration of action ranges from 8 weeks to 5 years. Despite the advantages of long-acting reversible hormonal contraceptive methods, they are infrequently used in South Africa. Short-acting methods, specifically oral contraceptives and condoms, are by far the most commonly used reversible methods. A shift from the use of short-acting methods to long-acting reversible contraceptive methods could help reduce the high rates of unintended pregnancies in South Africa. In this review of long-acting reversible hormonal contraceptive methods, we discuss the long-acting progesterone injectables, the etonogestrel implant and the levonorgestrel intrauterine system available in South Africa, the side effects of each of these preparations and the non-contraceptive benefits. It is imperative that health professionals and educators inform women of reproductive age about the benefits, risks, and common side effects of long-acting reversible hormonal contraception to improve consideration and recognition of these methods.
\end{abstract}

Keywords: long-acting reversible hormonal contraception, progestogen-only injectables, subdermal implants, levonorgestrel intrauterine contraception

\section{Introduction}

Despite the significant amount of research and advances in contraceptive developments, ill-timed and unintended pregnancies continue to be a global concern. ${ }^{1}$ Family planning is crucial to reduce unsustainable population growth and the resulting negative impacts on the economy, environment, health and national development efforts. Women should be encouraged to discuss their fertility plans at clinical consultations, which should follow an integrated and transparent clinical approach. This approach may introduce the woman to a variety of contraceptive methods, remembering that she may have other issues and concerns related to fertility intentions. If necessary, preconception counselling should be offered. There is also a tendency to feminise contraception based on the perception that it is a woman's issue and responsibility,

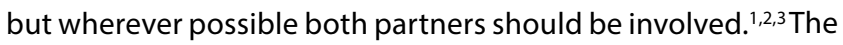
use of hormonal contraception has increased in many parts of the world, especially in high population countries in Asia and Latin America, yet remains low in sub-Saharan Africa. ${ }^{2}$

When deciding on a hormonal contraceptive method, women should consider different factors such as cost, efficacy, accessibility, adverse effects, potential advantages, return to fertility and non-contraceptive benefits. In order to enable and facilitate selection of an optimal contraceptive method that will be successful for a specific individual, contraceptive counselling provides education and encourages patient involvement in healthcare decisions. ${ }^{3}$

Long-acting reversible hormonal contraceptives are methods of birth control that provide effective contraception for an extended period of time without requiring user action. They include injections, intrauterine hormonal-releasing devices (IUD) and subdermal contraceptive implants. They are the most effective reversible methods of contraception as they do not depend on patient compliance. In addition to having a long duration of action, convenience, and being well liked by users, they are very cost effective. ${ }^{1}$ Despite their safety and effectiveness, long-acting reversible hormonal contraceptives are underutilised worldwide. About $5 \%$ of women use the progesterone injectables, $14 \%$ of women use IUD, and $3.4 \%$ use subdermal implants. ${ }^{4}$

Female sterilisation and the IUD are the two most common methods used by married or sexually active women worldwide. In 2015, approximately $19 \%$ of women relied on female sterilisation and $14 \%$ used the IUD. Short-term methods are less 
common; $9 \%$ of women used the pill in $2015,8 \%$ relied on male condoms and $5 \%$ used injectables. Only $6 \%$ of married or inunion women worldwide used rhythm or withdrawal. ${ }^{4,5}$ Longacting reversible hormonal contraceptive methods are both reversible and highly effective as they do not rely on patient compliance and precise attention to timing in the same way as pills or barrier methods.

The World Health Organization (WHO) has online tools available to assist in choosing the most suitable form of contraception. The WHO Medical Eligibility Criteria for Contraceptive Use (WHO MEC) provides evidence-based recommendations to ensure that patients are medically suited for a particular method and can safely select the most appropriate method of contraception. ${ }^{1}$ This article guides the choices available in South Africa.

\section{Progestogen-only injectables}

The progestogen-only injectables contain synthetic progestogen administered by a deep intramuscular injection. The progestogenonly injectables are favoured among many women because they are highly effective, easy to comply with and require only periodic clinical visits. Progestogen-only injectable contraceptives offer the advantages of not requiring special storage making them suitable for use in third world countries such as South Africa. There are two available preparations widely used in South Africa namely depot medroxyprogesterone acetate (DMPA), and norethisterone enanthate (NET-EN). ${ }^{6}$ Depot medroxyprogesterone acetate $150 \mathrm{mg}$ (DMPA, Petogen ${ }^{\oplus}$ ) is administered intramuscularly every 12 weeks and norethisterone enanthate $200 \mathrm{mg}$ (Nur-Isterate ${ }^{\circledast}$ ) is administered every eight weeks. ${ }^{7}$

The principal mechanism of action is by the suppression of ovulation by interfering with the mid-cycle production of luteinizing hormone and causing morphological changes in the endometrium which renders implantation of the fertilised ovum difficult. They also cause thickening of the cervical mucus which renders it impervious to spermatozoa, hence preventing the ascent of sperm into the uterine cavity. ${ }^{8}$ DMPA is a highly reliable long-acting reversible contraception, with a failure rate of about $0.2 \% .9,10$

During the first months of use, the most common side effects are irregular bleeding and spotting lasting seven days or longer, the changes in menstrual patterns may result in secondary amenorrhea and breakthrough bleeding, weight gain, headaches, a delay in ovulation when the injections are discontinued and thus a delay in the return to fertility. One of the main concerns of depot medroxyprogesterone acetate is a temporary reduction in bone mineral density as DMPA reduces the ovarian production of estradiol. Several studies suggest that the bone mineral density that diminishes during use of DMPA recovers after discontinuation of the injection. ${ }^{11}$

\section{Etonogestrel subdermal implant}

Long-acting progestogen subdermal implants are proven to be highly effective and safe, and also have some additional non-contraceptive benefits. In South Africa, one type of a subdermal etonogestrel implant is available and is marketed as Implanon ${ }^{\circledR}$ NXT. Implanon ${ }^{\circledR}$ NXT is a small plastic, single-rod contraceptive implant measuring $40 \mathrm{~mm} \times 2 \mathrm{~mm}$, containing $68 \mathrm{mg}$ of etonogestrel (the active metabolite of desogestrel) and delivering a daily dose sufficient to suppress ovulation over a 3-year period. ${ }^{12}$ It is placed just under the skin of the upper arm that releases small amounts of the progestogen into the body. Implanon ${ }^{\circledR}$ NXT contains no estrogen and is therefore suitable for most women, including those who are breastfeeding, or do not wish to use estrogen. ${ }^{13}$ The etonogestrel implant has been shown to be a very effective form of contraception, with extremely low failure rates and high continuation rates. ${ }^{14}$

The insertion and removal of the etonogestrel implant has to be done by a trained health care professional. The blood levels of etonogestrel hormone released by the implant is constant and considerably lower than with the progestogen-only injectables, therefore side effects, although comparable to those of the progestogen injections, are less severe and are reversed shortly after the implant is removed. ${ }^{15}$ The most common side effects are irregular bleeding, headaches, weight gain, acne, breast tenderness, emotional lability and abdominal pain. ${ }^{15}$ Unlike the progestogen injectables, the etonogestrel subdermal implant has no effect on bone mineral density. ${ }^{16}$ According to the World Health Organization (WHO) level 4 guidelines, the subdermal implant should not be used in women with a known or suspected pregnancy, women who have a history of blood clots (deep vein thrombosis or pulmonary embolism), liver disease or jaundice, breast or other progesterone dependent cancers, porphyria or unexplained vaginal bleeding. ${ }^{17}$

Potent enzyme-inducing medications, for example rifampicin, efavirenz, carbamazepine, phenobarbital and phenytoin may interact with Implanon ${ }^{\circledast}$ NXT by increasing the rate of metabolism of etonogestrel, thus reducing the contraceptive plasma levels and efficacy. As a result, additional non-hormonal contraception is necessary for 28 days after taking any enzymeinducing agents. ${ }^{6}$

\section{Levonorgestrel-releasing intrauterine system}

Approximately $14.3 \%$ of women worldwide use intrauterine contraception although in Southern African countries, the use of intrauterine contraception is less than $2 \% .^{18}$ In South Africa, the intrauterine contraceptives available for local use include the Plastic IUD with copper (CUT 380A) and the levonorgestrel intrauterine system (Mirena $\left.{ }^{\oplus}\right)^{6}{ }^{6}$ Since this review is focused on long acting reversible hormonal contraceptives, only the levonorgestrel intrauterine system will be discussed.

The levonorgestrel intrauterine system (LNG-IUS) is a plastic, T-shaped device with a cylindrical-shaped reservoir containing $52 \mathrm{mg}$ levonorgestrel, releasing $20 \mathrm{mcg}$ per 24 hours, and is effective for five years. The levonorgestrel intrauterine system available in South Africa is branded as Mirena ${ }^{\circledR}$. Its mechanism of action is based on local effects within the uterine cavity and includes thickening of cervical mucus, disruption of normal function and movement of sperm inside the uterus and fallopian tubes and a reduction in endometrial growth. ${ }^{19,20}$ 
Table I: Characteristics of the progestogen-only injectables (DMPA, Petogen ${ }^{\circledR}$, and Nur-Isterate ${ }^{\circledR}$ ), the etonogestrel subdermal implant $\left(\right.$ Implanon ${ }^{\circledR}$ NXT) and the levonorgestrel intrauterine system (Mirena ${ }^{\circledR}$ )

\begin{tabular}{|c|c|c|c|}
\hline & Progestogen-only Injectables & Etonogestrel implant & Levonorgestrel-IUS \\
\hline & $\begin{array}{l}\text { DMPA, Petogen }{ }^{\circledast}, \\
\text { Nur-Isterate }^{\circledast}\end{array}$ & Implanon ${ }^{\circledR}$ NXT & Mirena ${ }^{\circledR}$ \\
\hline Mechanism of action & $\begin{array}{l}\text { Inhibits ovulation, thickens cervical } \\
\text { mucus, prevents sperm penetration }\end{array}$ & $\begin{array}{l}\text { Primarily inhibits ovulation, } \\
\text { thickens cervical mucus, prevents } \\
\text { sperm penetration }\end{array}$ & $\begin{array}{l}\text { Thickens cervical mucus } \\
\text { and suppresses endometrial } \\
\text { development }\end{array}$ \\
\hline Side effects & $\begin{array}{l}\text { Changes in menstrual bleeding } \\
\text { (irregular, prolonged or/and } \\
\text { heavy bleeding, amenorrhoea) } \\
\text { and weight gain, Other possible } \\
\text { side effects include headaches, } \\
\text { dizziness, mood changes and } \\
\text { decrease in sex drive }\end{array}$ & $\begin{array}{l}\text { Changes in menstrual bleeding } \\
\text { are common, including lighter } \\
\text { bleeding, irregular bleeding, } \\
\text { infrequent bleeding and } \\
\text { amenorrhoea. Other side effects } \\
\text { include headaches, nausea, } \\
\text { dizziness, breast tenderness, mood } \\
\text { changes and abdominal pain due } \\
\text { to enlarged ovarian follicles }\end{array}$ & $\begin{array}{l}\text { Light irregular bleeding and } \\
\text { infrequent bleeding are common } \\
\text { initially with increasing risk of } \\
\text { amenorrhoea later }\end{array}$ \\
\hline Non-contraceptive benefits & $\begin{array}{l}\text { Prevention or improvement of iron } \\
\text { deficiency anaemia } \\
\text { Decrease in occurrence of ectopic } \\
\text { pregnancy, pelvic inflammatory } \\
\text { disease, uterine fibroids and } \\
\text { endometrial cancer } \\
\text { Reduction in symptoms of } \\
\text { endometriosis }\end{array}$ & $\begin{array}{l}\text { Prevention of symptomatic PID } \\
\text { and iron-deficiency anaemia }\end{array}$ & $\begin{array}{l}\text { Reduction in menstrual blood } \\
\text { loss and thus prevention or } \\
\text { improvement of iron-deficiency } \\
\text { anaemia; protection against } \\
\text { ectopic pregnancy; reduction in } \\
\text { menstrual cramps and symptoms } \\
\text { of endometriosis }\end{array}$ \\
\hline Duration of use & $\begin{array}{l}\text { Can be used throughout a } \\
\text { woman's reproductive years but } \\
\text { perimenopausal women may not } \\
\text { have enough time until menopause } \\
\text { to regain bone density. Switching } \\
\text { to another method after reaching } \\
45 \text { years should be considered }\end{array}$ & $\begin{array}{l}\text { Can be used throughout the } \\
\text { reproductive years }\end{array}$ & 5 years \\
\hline Return to fertility & $\begin{array}{l}\text { Delay of about } 4 \text { to } 6 \text { months } \\
\text { depending on the type of } \\
\text { injectable }\end{array}$ & No delay & No delay \\
\hline
\end{tabular}

The most common side effects of the levonorgestrel intrauterine system are irregular/unscheduled bleeding, spotting and amenorrhea. ${ }^{6}$ The changes in bleeding patterns are a side effect of levonorgestrel on the uterine lining and are not dangerous. ${ }^{21}$

The LNG-IUS has many non-contraceptive benefits, which include the treatment of heavy menstrual bleeding, dysmenorrhoea and pain associated with endometriosis, no delay in the return to fertility, minimal patient compliance and reduced cost with long term use. 2,20,22,23 It can also be used in women with endometrial hyperplasia and as endometrial protection for those on oestrogen replacement therapy. ${ }^{24}$

When compared to the etonogestrel implant, the levonorgestrel intrauterine system has fewer systemic hormonal side effects, a decrease in the risk of unscheduled bleeding, and a longer duration of action. However, the etonogestrel implant is a good option for women who do not want to or cannot use the levonorgestrel intrauterine system, as it is more effective at preventing pregnancy than short-acting reversible method. The etonogestrel implant also provides more reliable ovulation suppression for women with medical conditions sensitive to endogenous hormonal fluctuations. Table 1 provides a summary of all the main characteristics of the progestogenonly injectables, the etonogestrel subdermal implant and the levonorgestrel intrauterine system.

\section{Conclusion}

Long-acting reversible hormonal contraceptives are safe and reversible, require very little maintenance and have improved compliance rates compared to other hormonal methods. For this reason they are ideal pregnancy prevention options for many young women of reproductive age. Young women who are sexually active and are at a high risk of unintended pregnancy, should be encouraged to consider long-acting reversible hormonal contraceptives as a contraceptive option. Health professionals and educators should include information about the benefits of long-acting reversible hormonal contraception, the side effects and the return to fertility in discussions of birth control options as well as information regarding sexually transmitted diseases. 


\section{References}

1. World Health Organization (WHO). Family Planning. Fact sheet no. 351; [updated May 2015; cited 3 August 2016]. Available from: http://who.int/mediacentre/ factsheets/fs351/en/

2. World Health Organization (WHO). Medical Eligibility Criteria for Contraceptive Use. 5th ed. Geneva: WHO; 2015 [cited 3 August 2016]. Available from: http:// apps.who.int/iris/bitstream/10665/181468/1/9789241549158_eng.pdf?ua=1.

3. Kavanaugh $M L$, Frohwirth $L$, Jerman J, Popkin $\mathrm{R}$, et al. Long-acting reversible contraception for adolescents and young adults: patient and provider perspectives. J Pediatr Adolesc Gynecol. 2013;26(2):86-95.

4. United Nations. Trends in contraceptive methods used worldwide. Population facts No. 2015 [cited 26 July 2016]. Available from: http:// www.un.org/en/development/desa/population/publications/pdf/family/ trendsContraceptiveUse2015Report.pdf

5. Melville C, Bigrigg A. Male and female sterilization. Obstet, Gynecol Reprod Med. 2008;18:330-4

6. Rossiter D, Blockman M, Barnes Kl, Cohen K, Decloedt E, Irhuma M, et al. eds. South African Medicines Formulary. 12th ed. Cape Town: South African Medical Association Health and Publishing Group; 2014.

7. D'Arcangues C, Snow R. Injectable contraceptives. In: Rabe T, Runnebaum B, editors. Fertility control: update and trends. Berlin: Springer-Verlag. 1999;121-49.

8. Kaunitz AM. Long-acting injectable contraception with depot medroxyprogesterone acetate. Am J Obstet Gynecol. 1994;170:1543.

9. National Institute for Health and Care Excellence. Long-acting reversible contraception. PubMed Health. [cited 20 May 2016]. Available from: http://www. ncbi.nlm.nih.gov/books/NBK51051/

10. Trussell J. Contraceptive failure in the United States. Contraception. 2011;83:397.

11. Beksinska ME, Kleinschmidt I, Smit JA, Farley TM. Bone mineral density and use of depot medroxyprogesterone acetate (DMPA), norethisterone enanthate (NET-EN) and combined oral contraceptives. Contraception. 2009;79(5):345-9.

12. Flores JB, Balderas ML, Bonilla MC, Vazquez-Estrada I. Clinical experience and acceptability of the Etonogestrel subdermal contraceptive implant. Int J Gynecol Obstet. 2005;90(3):228-33.
13. Curtis KM, Tepper NK, Jatlaoui TC, et al. U.S. Medical Eligibility Criteria for Contraceptive Use. Morbidity and Mortality Weekly Report, Recommendations and Reports. 2016;65(3).

14. Graesslin O, Korver T. The contraceptive efficacy of Implanon: A review of clinical trials and marketing experience. Eur J Contracept Reprod Health Care. 2008;3 Suppl 1:4-12.

15. Raymond EG. Contraceptive Implants. Contraceptive Technology. 19th ed. New York: Ardent Media; 2007. p. 145-56.

16. Bahamondes L, Monteiro-Dantas C, Espejo-Arce X, et al. A prospective study of the forearm bone density of users of etonogestrel and levonorgestrel-releasing contraceptive implants. Hum Reprod. 21:466-70.

17. Bahamondes L. Interventions Subdermal implantable contraceptives versus other forms of reversible contraceptives or other implants as effective methods of preventing pregnancy. The WHO Reproductive Health Library; Geneva: World Health Organization. [cited 23 June 2016]. Available from: http://apps.who.int/ rhl/fertility/contraception/CD001326_bahamondesl_com/en/

18. Buhling KJ, Zite NB, Lotke $P$, et al. Worldwide use of intrauterine contraception: a review. Contraception. 2014; 89:162.

19. Mirena package insert. [cited 29 July 2016]. Available from: http://labeling. bayerhealthcare.com/html/products/pi/Mirena_Pl.pdf

20. Lewis RA, Taylor D, Natavio MF, et al. Effects of the levonorgestrel-releasing intrauterine system on cervical mucus quality and sperm penetrability. Contraception. 2010;82:491.

21. Diedrich JT, Desai S, Zhao Q, et al. Association of short-term bleeding and cramping patterns with long-acting reversible contraceptive method satisfaction. Am J Obstet Gynecol. 2015;212(50)e1-50.

22. Thonneau PF, Almont T. Contraceptive efficacy of intrauterine devices. Am J Obstet Gynecol. 2008; 198:248.

23. Espey E, Ogburn T. Long-Acting Reversible Contracep $\neg$ tives: Intrauterine Devices and the Contraceptive Implant. Obstet Gynecol. 2011; 117(3): 705-19.

24. Wan YL, Holland C. The efficacy of levonorgestrel intrauterine systems for endometrial protection: a systematic review. Climacteric 2011; 14:622.

25. Fleming CF. Long acting reversible contraceptives. The Obstetrician \& Gynaecologist. 2009;11:83-88. 